\title{
The role of thiol-disulfide and ischemia-modified albumin levels in the diagnosis of childhood appendicitis
}

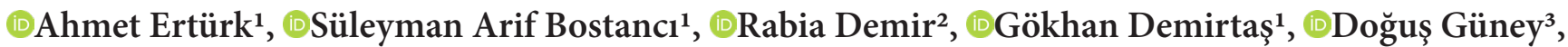

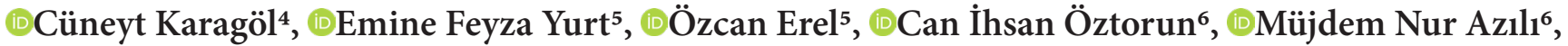 \\ (1)Emrah Şenel ${ }^{6}$ \\ ${ }^{1}$ Ankara City Hospital, Pediatric Surgery Clinic, Ankara, Turkey \\ ${ }^{2}$ Şırnak State Hospital, Pediatric Surgery Clinic, Şırnak, Turkey \\ ${ }^{3}$ Ankara Yildırım Beyazıt University, Department of Pediatric Surgery, Ankara, Turkey \\ ${ }^{4}$ Ankara City Hospital, Pediatric Clinic, Ankara, Turkey \\ ${ }^{5}$ Ankara Yıldırım Beyazıt University, Department of Biochemistry, Ankara, Turkey \\ ${ }^{6}$ Ankara Yıldırım Beyazıt University, Department of Pediatric Surgery, Ankara, Turkey
}

Cite this article as: Ertürk A, Bostancı S, Demir R, et al. The role of thiol-disulfide and ischemia-modified albumin levels in the diagnosis of childhood appendicitis. Anatolian Curr Med J 2021; 3(3); 214-219.

\begin{abstract}
Aim: The accurate diagnosis of acute appendicitis can be achieved by a combination of evaluation of clinical symptoms, physical examination findings and history taking, but is still challenging for the clinician. Some biochemical markers have been evaluated for the purpose of increasing the diagnostic accuracy rate for appendicitis. In this study, our aim is to evaluate the diagnostic value of thiol-disulfide levels and IMA, in pediatric patients with suspected acute appendicitis.

Material And Method: The children (1-17 years age) who were admitted to our clinic for suspected acute appendicitis between March 2017 and September 2017 were evaluated. A total of 238 children are enrolled in the study; 119 were operated for suspected acute appendicitis and the 119 children who did not have appendicitis constituted the control group. Serum levels of native thiol (-SH), total thiol (SH+SS), dynamic disulfide (SS), dynamic disulfide (SS)/total thiol (SH+SS) ratio, albumin, ischemic modified albumin (IMA) and WBC levels were obtained and compared within groups.

Results: The mean age of the patients was 10.9 years ( $\pm 3.7,3-17$ years) and 9.1 years ( $\pm 3.7,1-17$ years) in the operation and the control groups, respectively. The SH, SH+SS, SS and albumin levels and SS/SH+SS ratio were significantly lower and IMA levels were significantly higher in the operation group than the control group. Among the operated patients, IMA and dynamic disulfide levels were significantly higher and WBC levels were significantly lower in patients with non-perforated appendicitis than patients with perforated appendicitis. A significant decrease in serum levels of IMA was observed in the postoperative 1st day when compared with the preoperative values.

Conclusion: Measuring the IMA levels with thiol/disulfide homeostasis may increase the diagnostic accuracy rate when evaluating the patients with suspected appendicitis. However, it appears that these evaluations fail to distinguish the patients with perforated and non-perforated appendicitis, thus further studies are necessary.
\end{abstract}

Keywords: Appendicitis, oxidative stress, children, thiol-disulfide

\section{INTRODUCTION}

Acute appendicitis (AA) is one of the most common cause of surgical intervention in children (1). The establishment of diagnosis requires a combination of evaluating the clinical symptoms, physical examination and patients' history. However, as findings commonly overlap with many other conditions, accurate diagnosis is still challenging. In the English literature, negative appendectomy and perforated appendicitis rates are

reported around $12.2 \%$ and $3.4 \%$, respectively $(2,3)$. Imaging modalities (plain X-rays, ultrasonography, computerized tomography) and laboratory tests (WBC, C-reactive protein) may be helpful. WBC and CRP levels may help but not highly specific for the condition. Many scoring systems were proposed (like Alvarado) in an effort to increase the preoperative diagnostic accuracy (4). 
During the process of acute appendicitis, the integrity of the mucosal barrier is damaged due to obstruction of the appendiceal lumen and the resultant inflammatory response increases the tissue levels of neutrophils and other inflammatory cells. These cells release soluble mediators such as proinflammatory cytokines like (IL1, IL-6 and IL-8), tumor necrosis factor- $\alpha$ (TNF- $\alpha$ ), interferon-gamma (INF- $\mathrm{Y}$ ), and anti-inflammatory cytokines (IL-4 and IL-10). Increased serum levels of interleukins like IL-6, IL-8 and IL-10 are proposed to be helpful in the diagnosis of AA $(5,6)$. Nevertheless, a specific test for accurate diagnosis of AA is still lacking.

\section{Oxidative Stress}

Free radicals are highly reactive molecules that contain one or more unpaired electrons which emerge during cellular metabolism. The balance between the production of free radicals and antioxidant defense is regulated by delicate mechanisms which are essential in the physiology and for the survival of living organisms (7). A trend to oxidative process results in oxidative stress (OS) producing increased production of free oxygen radicals (FOR) and consequently damages the cellular structures, nucleic acids, lipids and proteins (8).

During the inflammatory process, OS is accelerated due to neutrophil and macrophage activation and over-production of FORs (9-11). FORs released by the polymorphonuclear leucocytes cause peroxidation of the lipids of the cellular membrane. Microvascular permeability increases consequently resulting in edema, infiltration by the inflammatory cells, neutrophil activation and finally cellular death (10).

\section{Thiol/Disulfide Balance}

Thiols, also known as mercaptans, are organic compounds composed of a central carbon atom attached with a sulfur and a hydrogen atoms that contain a sulfhydryl (-SH) group (12). Thiol compounds in the plasma act as antioxidants by binding free radicals for scavenging (13). Thiols (RSH) react with free radicals forming disulfide (RSSR) bonds. Resultant disulfide bonds are degraded back to thiol groups in order to maintain the dynamic thiol-disulfide homeostasis of the organism (12).

Disturbances in the dynamic thiol-disulfide homeostasis and resultant oxidative stress are accused to play a role in the pathogenesis of many disease processes like diabetes, cardiovascular diseases, cancer, Rheumatoid Arthritis, chronic kidney disease, AIDS, Parkinson's Disease, Alzheimer's Disease, Friedrich's ataxia, multiple sclerosis, amyotrophic lateral sclerosis, and liver diseases $(12,14)$. Accordingly, determination of the dynamic thiol/disulfide balance may provide valuable information about various normal or pathological biochemical processes (12).
Evaluation of oxidative stress in humans can be performed by either analyzing the products that emerged during oxidative damage or by determining the defensive antioxidant capacity of the organism (15). Erel et al. (12) developed a novel method that measures thiol/disulfide homeostasis in order to evaluate the oxidative stress level of the body, and the validity of the technique as a reliable indicator of OS is confirmed by many others (16-20).

\section{Ischemia-Modified Albumin (IMA)}

Ischemia-modified albümin is a novel cardiac marker approved by the FDA (21). The principle of the test is to measure the cobalt binding capacity of the albümin which is altered by the oxidative free radicals that emerged during the process of ischemia that leads to chemical alterations on the albumin itself. This altered albumin molecule loses its cobalt binding capability and is an early marker of ischemia (22). Recent research provided new perspectives that cardiac ischemia marker IMA may also provide useful information in various conditions (23-25). In this study, we aimed to evaluate if the disturbances in thiol-disulfide homeostasis can be a useful marker for the diagnosis of AA in children.

\section{MATERIAL AND METHOD}

The study was carried out with the permission of Clinical Researches Ethics Committee of Ankara Child Health and Diseases Hematology Oncology Training and Research Hospital (Date: 27.03.2017, Decision No: 2017-005). The study was designed prospectively. All procedures were carried out in accordance with the ethical rules and the principles of the Declaration of Helsinki.

A total of 238 patients are enrolled in the study and 2 groups were formed; Appendicitis Group $(\mathrm{n}=119)$ and Control Group $(\mathrm{n}=119)$. The 119 children $(0-18$ years of age) who underwent appendectomy between March 2017 and September 2017 are enrolled in the Appendicitis Group. A gender and age-matched cohort of 119 children who underwent circumcision without preputial inflammation and inguinal herniorrhaphy without incarceration are enrolled in the Control Group. Informed consent was obtained from the patients' parents or legal guardians.

For the patients with appendicitis, $2 \mathrm{~mL}$ blood samples were drawn into tubes with yellow cap and gel (BD Vacutainer plastic SST II tube ${ }^{\circledR}$ ) before the procedure, on the first day after surgery; an additional sample was taken on the postoperative day 5 if the patient had perforated appendicitis. Samples were centrifuged 10 minutes with $3600 \mathrm{rpm}$ and $2 \mathrm{cc}$ serum is extracted which was stored at -800 temperature. All the samples were defrozen at the same time and blood thiol-sulfide measurements were performed by a novel automatic method developed by Erel and Neselioglu (12), and IMA levels were measured 
by a colorimetric method developed by Bar-Or et al. (26) with Roche Hitachi Cobas c501 automatic analyzer device in the Biochemistry Laboratory of Ankara Atatürk Education And Research Hospital. With this technique, disulfide levels can also be measured together with thiol levels (which is also referred to as native thiol). The sum of the native thiol and disulfide levels is called total thiol (27). The serum levels of native thiol (-SH), total thiol (SH+SS), dynamic disulfide (SS), \% dynamic disulfide (SS)/total thiol $(\mathrm{SH}+\mathrm{SS})$, albümin, IMA and WBC were measured. Statistical analyses are performed between the groups, and between the subgroups of patients with perforated and nonperforated appendicitis in the Appendicitis Group.

\section{Statistical Analysis}

Statistical analyses were performed with the SPSS ((Statistical Package for Social Sciences) software version 17 (Chicago, USA). On evaluation of normality of the numerical variables, native thiol $(\mathrm{SH})$, total thiol (SS+SH), dynamic disulfide (SS), \% dynamic disulfide (SS)/total thiol, IMA, albumin and WBC values are found not normally distributed. Descriptive analyses of the numerical variables that do not distribute normally were performed with the Mann-Whitney $U$ test by mean values. Categorical variables were compared Chisquare test. Preoperative, postoperative 1st and 5th days values of dynamic disulfide (SS), native thiol, total thiol, $\%$ dynamic disulfide (SS)/total thiol (SS+SH), IMA ve albümin values were analyzed with paired correlation test. A $p<0.05$ value is considered statistically significant.

\section{RESULTS}

In the Appendicitis Group, 36\% $(n=43)$ of the patients had perforated and 64\% $(n=76)$ had non-perforated appendicitis. Appendectomy was performed with laparoscopic technique in $12.5 \%(\mathrm{n}=16)$ and open technique in $87.5 \%(\mathrm{n}=103)$.

\section{The Demographic Results}

The rates and numbers of girls and boys were the same in both groups with $40.3 \%(n=48)$ girls and $59.7 \%(n=71)$ boys. The mean age of the patients was 11,51 years (Min$\mathrm{Max}=7.0-17.0$, Std $\mathrm{Dev}=2.86$ ) and 12,34 years (MinMax=6.0-17.0, Std. Dev=3.35) in the control and study groups, respectively. the gender and age of the patients were not significantly different between the groups $(\mathrm{p}=0.30$ and $\mathrm{p}=0.59$, respectively) (Table $\mathbf{1}$ ).

\section{Laboratory Results}

$\mathrm{SH}, \mathrm{SS}+\mathrm{SH}, \mathrm{SS}, \mathrm{SS} / \mathrm{SH}+\mathrm{SS} \%$, IMA, albumin and WBC levels of the groups and statistical analyses are given in Table 2.

The SH $(p<0.001)$, SH+SS $(p<0.001)$, dynamic thiol $(\mathrm{p}<0.001)$ levels, calculated $\mathrm{SS} / \mathrm{SH}+\mathrm{SS}$ ratio $(\mathrm{p}<0.001)$, and albumin $(p<0.001)$ were found significantly lower in the Appendicitis Group, whereas IMA levels $(\mathrm{p}<0.001)$ were found significantly higher (Table 2). WBC levels were significantly higher in the Appendicitis Group $(\mathrm{p}<0.001)$

The comparison of the laboratory findings between the patients with perforated $(n=43)$ and non-perforated $(\mathrm{n}=76)$ appendicitis in the Appendectomy Group are given in Table 3.

Only IMA, dynamic disulfide and WBC were significantly different between the groups. On subgroup evaluation, WBC levels were found significantly lower in patients with non-perforated appendicitis while IMA and dynamic disulfide levels were significantly higher in patients with perforated appendicitis $(\mathrm{p}=0.03, \mathrm{p}=0,001$, and $\mathrm{p}=0,038$, respectively).

The details about the comparison of SH, SS+SH, SS, SS/ $\mathrm{SH}+\mathrm{SS} \%$, IMA, and albumin levels on the preoperative and the 1st day after the operation in the Appendicitis Group are given in Table 4. A significant decrease in the IMA levels is found $(\mathrm{p}=0.028)$. When native thiol $(\mathrm{SH})$, total thiol (SS+SH), dynamic disulfide (SS), \% dynamic disulfide/ total thiol, IMA, and albümin levels on preoperative and $5^{\text {th }}$ day after the operation were compared, no significant change was found ( $p>0.05)$.

\begin{tabular}{|c|c|c|c|}
\hline Variables & $\begin{array}{c}\begin{array}{c}\text { Appendicitis group } \\
\mathrm{n}=119\end{array} \\
\end{array}$ & $\begin{array}{c}\begin{array}{c}\text { Control group } \\
n=119\end{array} \\
\end{array}$ & p value \\
\hline Age (years)* & $10.9(3-17 ; 3.7)$ & $9.1(1-17 ; 3.7)$ & $0.72^{\dagger}$ \\
\hline \multicolumn{4}{|l|}{ Gender, n (\%) } \\
\hline Male & $71(59.7)$ & $71(59.7)$ & \multirow{2}{*}{$1.00^{\ddagger}$} \\
\hline Female & $48(40.3)$ & $48(40.3)$ & \\
\hline
\end{tabular}

\begin{tabular}{|c|c|c|c|}
\hline Variables & Appendicitis (n=119) Mean (Min-Max; SD) & Control (n=119) Mean (Min-Max; SD) & P value \\
\hline Native thiol (SH) & $341.54(171.9-574.8 ; 67.93)$ & $408.25(259.3-673.2 ; 63.62)$ & $<0.001$ \\
\hline Total thiol (SS+SH) & $370.27(181.8-632 ; 74.41)$ & $448.21(279.6-742.5 ; 69.35)$ & $<0.001$ \\
\hline Dynamic disulfide (SS) & $14.35(5-29 ; 3,67)$ & $19.97(10-35 ; 4.41)$ & $<0.001$ \\
\hline Dynamic disulfide/Total thiol, \% & $3.85(2.55-5.24 ; 0.50)$ & $4.46(3.11-7.77 ; 0.77)$ & $<0.001$ \\
\hline Ischemia-modified albumin & $0.82(0.38-1.43 ; 0.20)$ & $0.62(0.26-1.31 ; 0.17)$ & $<0.001$ \\
\hline Albumin & $4.19(1.9-6.1 ; 0.69)$ & $4.53(3.7-6 ; 0.42)$ & $<0.001$ \\
\hline White blood count (WBC) & $14.77(4.3-34.2 ; 5.29)$ & $9.42(4.10-13.76 ; 4.56)$ & $<0.001$ \\
\hline
\end{tabular}




\begin{tabular}{|c|c|c|c|}
\hline Variables & $\begin{array}{c}\text { Non-perforated Appendicitis }(n=76) \\
\text { Mean (Min-Max; SD) }\end{array}$ & $\begin{array}{c}\text { Perforated Appendicitis }(n=43) \\
\text { Mean (Min-Max; SD) }\end{array}$ & P value ${ }^{*}$ \\
\hline Native thiol (SH) & $350.78(212.9-574.8 ; 59.18)$ & $352.22(171.9-463.7 ; 79.26)$ & 0.110 \\
\hline Total thiol (SS+SH) & $380.74(227-632 ; 65.13)$ & $351.76(181.8-504.3 ; 86.21)$ & 0.09 \\
\hline Dynamic disulfide (SS) & $14.96(7-29 ; 3.48)$ & $13.28(5-20 ; 3.78)$ & 0.038 \\
\hline Dynamic disulfide/Total thiol, \% & $3.90(2.55-5.24 ; 0.49)$ & $3.75(2.75-5.13 ; 0.51)$ & 0.100 \\
\hline Ischemia-modified albumin & $0.77(0.38-1.35 ; 0.18)$ & $0.90(0.45-1.43 ; 0.21)$ & 0.001 \\
\hline Albumin & $4.32(1.9-6.1 ; 0.21)$ & $3.96(2-5.2 ; 0.79)$ & 0.27 \\
\hline White blood count (WBC) & $13.46(4.9-25 ; 4.64)$ & $17.09(4.3-34.2 ; 5.63)$ & $<0.001$ \\
\hline
\end{tabular}

\begin{tabular}{|c|c|c|c|}
\hline Variables & $\begin{array}{c}\text { Pre-op levels } \\
\text { Mean (Min-Max; SD) }\end{array}$ & $\begin{array}{l}\text { Post-op 1st day level } \\
\text { Mean (Min-Max; SD) }\end{array}$ & P value ${ }^{\star}$ \\
\hline Native thiol (SH) & $341.54(171.9-574.8 ; 67.93)$ & $408.25(259.3-673.2 ; 63.62)$ & 0.063 \\
\hline Total thiol $(\mathrm{SS}+\mathrm{SH})$ & $370.27(181.8-632 ; 74.41)$ & $352.88(177.8-466.5 ; 50.98)$ & 0.068 \\
\hline Dynamic disulfide (SS) & $14.35(5-29 ; 3.67)$ & $13.62(5-18 ; 2.81)$ & 0.254 \\
\hline Dynamic disulfide/Total thiol, \% & $3.85(2.55-5.24 ; 0.50)$ & $3.83(2.81-5.17 ; 0.50)$ & 0.959 \\
\hline Ischemia-modified albumin & $0.82(0.38-1.43 ; 0.20)$ & $0.74(0.45-1.36 ; 0.20)$ & 0.028 \\
\hline Albumin & $4.19(1.9-6.1 ; 0.69)$ & $4.26(2.3-5.4 ; 0.57)$ & 0.587 \\
\hline
\end{tabular}

\section{DISCUSSION}

Findings of this study support that antioxidant representatives (including $\mathrm{SS}+\mathrm{SH}, \mathrm{SH}$ and albumin and oxidative side substrates as SS and SS/ $\mathrm{SH}+\mathrm{SS}$ ratios) have crucial roles on the thiol/disulfide homeostasis, and are found to decrease significantly in patients with acute appendicitis. Additionally, IMA levels demonstrated a significant increase in patients with acute appendicitis. IMA has become a significant molecule in the diagnosis of appendicitis (28). Yeniocak et al. (29) and Demir et al. (30) stated that serum IMA levels can be used as a diagnostic marker in patients with suspected acute appendicitis. These results indicate that the thiol/disulfide balance in the AA group shifts towards the oxidative side, resulting in increased OS levels.

Although some authors claim a contribution of increased OS in the etiology of AA, some others attribute the increased $O S$ as a result of the inflammation process initiated by the AA (31). The relationship between AA and OS has been investigated in several experimental and clinical studies $(3,11,32)$.

The data in children is quite limited (33). Dumlu et al. (3) demonstrated increased oxidative stress markers in the plasma and the appendiceal tissue in children with AA compared to the controls, suggesting that OS is higher in patients with acute appendicitis. they also hypothesized that OS might have a role in the pathogenesis of $\mathrm{AA}$ and OS might positively be correlated with the severity of the disease. Özyazıc1 et al. (18) demonstrated a trend towards the oxidant side in the thiol/disulfide balance in adult patients with AA. Yildirim et al. (5) found decreased SS+SH levels in adult patients with AA when compared to controls. These findings support the hypothesis of elevated oxidative stress in adults and children with AA, which is also supported by the results of our current study.

OS is reported to be higher in patients with perforated AA than patients with non-perforated AA (2,32-33). Koltuksuz et al. (34) demonstrated significantly higher OS in patients with perforated AA than patients with non-perforated AA and claimed that excessively elevated OS may indicate an advanced stage of AA. However, we could not demonstrate any significant difference in the thiol/disulfide balance between patients with perforated and non-perforated appendicitis, except SS. IMA levels of the patients with non-perforated AA were found significantly lower than the patients with perforated AA and SS levels were higher. Based on these findings, thiol /disulfide balance is not a useful laboratory marker for discrimination of the nonperforated and perforated acute appendicitis in children. The preoperative and postoperative 1st day $\mathrm{SH}+\mathrm{SS}, \mathrm{SH}$, SS, SS/ SH+SS ratio, albumin, and IMA levels were not significantly different.

In line with the current literature, we found significantly increased WBC levels in patients with AA $(35,36)$. We found decreased albumin and increased IMA levels in patients with AA than controls. IMA has been widely accepted as a marker of OS in various pathological processes. Increased IMA levels related to AA have been reported by many others $(3,34,36,37)$. Kilıç et al. (38) found significantly increased IMA levels in adult patients with AA and concluded that IMA can be used as an indicator of the severity of AA. Similarly, many other authors conclude that IMA can be used as a marker for the diagnosis of AA $(39,40)$.

Compatible with the current literature, we found higher IMA levels in patients with AA than controls. 


\section{CONCLUSION}

The differential diagnosis of AA in children is challenging due to the lack of a reliable laboratory test or imaging method. The development of a specific test for the diagnosis of AA may prevent unnecessary negative appendectomy rates and reduce the morbidity and mortality related to perforated appendicitis.

For this purpose, evaluating the thiol/disulfide homeostasis and demonstrating the elevated oxidative stress may be helpful for the differential diagnosis in patients with suspected AA. Although measuring the IMA levels and demonstrating the alterations in the thiol/disulfide homeostasis appear to be promising for increasing the specificity of the differential diagnosis process, discrimination of perforated and non-perforated AA do not look reliable, currently. Further clinical studies with prospective design and increased number of patients are necessary for validation of these results.

\section{ETHICAL DEVCLARATIONS}

Ethics Committee Approval: The study was carried out with the permission of Clinical Researches Ethics Committee of Ankara Child Health and Diseases Hematology Oncology Training and Research Hospital (Date: 27.03.2017, Decision No: 2017-005).

Informed Consent: All patients signed the free and informed consent form.

Referee Evaluation Process: Externally peer-reviewed.

Conflict of Interest Statement: The authors have no conflicts of interest to declare.

Financial Disclosure: The authors declared that this study has received no financial support.

Author Contributions: All of the authors declare that they have all participated in the design, execution, and analysis of the paper, and that they have approved the final version.

\section{REFERENCES}

1. Vahdad M.R, Nissen M, Semaan A, et al. Experiences with LESSappendectomy in Children. Arch Iran Med 2016; 19: 57.

2. Park JS, Jeong JH, Lee JI, Lee JH, Park JK, Moon HJ. Accuracies of diagnostic methods for acute appendicitis. Am Surg 2013; 79: 101-6.

3. Dumlu EG, Tokaç M, Bozkurt B, et al. Correlation between the serum and tissue levels of oxidative stress markers and the extent of inflammation in acute appendicitis. Clinics 2014; 69: 677-82

4. Mohammed AA, Daghman NA, Aboud SM, Oshibi HO. The diagnostic value of C-reactive protein, white blood cell count and neutrophil percentage in childhood appendicitis. Saudi Med J 2004; 25: 1212-5.

5. Yıldırım O, Solak C, Koçer B, et al. The role of serum inflammatory markers in acute appendicitis and their success in preventing negative laparotomy. J Invest Surg 2006; 19: 345-52.
6. Paajanen H, Mansikka A, Laato M, Ristamäki R, Pulkki K, Kostiainen S. Novel serum inflammatory markers in acute appendicitis. Scand J Clin Lab Invest 2002; 62: 579-84.

7. Saugstad OD. Mechanisms of tissue injury by oxygen radicals: implications for neonatal disease. Acta Paediatr 1996; 85: 1-4.

8. Valko M, Leibfritz D, Moncol J, Cronin MT, Mazur M, Telser J. Free radicals and antioxidants in normal physiological functions and human disease. Int J Biochem Cell Biol 2007; 39: 44-84.

9. Bolukbas C, Bolukbas FF, Horoz M, Aslan M, Celik H, Erel O. Increased oxidative stress associated with the severity of the liver disease in various forms of hepatitis B virus infection. BMC Infect Dis 2005; 5: 95.

10. Ozdogan M, Devay AO, Gurer A, et al. Plasma total anti-oxidant capacity correlates inversely with the extent of acute appendicitis: a case control study. World J Emerg Surg 2006; 1: 6.

11. Serefhanoglu K, Taskin A, Turan H, Timurkaynak FE, Arslan H, Erel O. Evaluation of oxidative status in patients with brucellosis. Braz J Infect Dis 2009; 13: 249-51.

12. Erel O, Neselioglu S. A novel and automated assay for thiol/ disulphide homeostasis. Clin Biochem 2014; 47: 326-32.

13. Hu M.L. Measurement of protein thiol groups and glutathione in plasma. Methods Enzymol 1994; 233: 380-5.

14. Abuja P.M, Albertini R. Methods for monitoring oxidative stress, lipid peroxidation and oxidation resistance of lipoproteins. Clin Chim Acta 2001; 306: 1-17.

15. De Oliveira Machado SL, Bagatini MD, Da Costa P, et al. Evaluation of mediators of oxidative stress and inflammation in patients with acute appendicitis. Biomarkers 2016; 21: 530-7.

16. Karadag-Oncel E, Erel O, Ozsurekci Y, et al. Plasma oxidative stress and total thiol levels in Crimean-Congo hemorrhagic fever. Jpn J Infect Dis 2014; 67: 22-6.

17. Dinc ME, Ozdemir C, Ayan NN, et al. Thiol/disulfide homeostasis as a novel indicator of oxidative stress in obstructive sleep apnea patients. Laryngoscope 2017; 127: 244-50.

18. Ozyazici S, Karateke F, Turan U, et al. A Novel oxidative stress mediator in acute appendicitis: thiol/disulphide homeostasis. Mediators Inflamm 2016:6761050.

19. Elmas B, Erel Ö, Ersavaş D, Yürümez Y. Thiol/disulfide homeostasis as a novel indicator of oxidative stress in children with simple febrile seizures. Neurol Sci 2017; 38: 1969-75.

20. Elmas B, Karacan M, Dervişoğlu P, Kösecik M, İşgüven ŞP, Bal C. Dynamic thiol/disulphide homeostasis as a novel indicator of oxidative stress in obese children and its relationship with inflammatory-cardiovascular markers. Anatol J Cardiol 2017; 18: 361-9.

21. Wudkowska A, Goch J, Goch A. Ischemia-modified albumin in differential diagnosis of acute coronary syndrome without ST elevation and unstable anginapectoris. Kardiol Pol 2010; 68: 431-7.

22. Aran T, Unsal MA, Güven S, Kart C, Cetin E, Alver A. Carbon dioxide pneumoperitoneum induces systemic oxidative stres: a clinical study. Eur J Obstet Gynecol Reprod Biol 2012; 161: 80-3.

23. Ma SG, Wei CL, Hong B, Yu WN. Ischemia-modified albumin in type 2 diabetic patients with and without peripheral arterial disease. Clinics 2011; 66: 1677-80.

24. Mastella AK, Moresco RN, da Silva DB, et al. Evaluation of ischemiamodified albumin in myocardial infarction and prostatic diseases. Biomed Pharmacother 2009; 63: 762-6.

25. Lippi G, Montagnana M. Ischemia Modified Albumin in Ischemic Disorders. Ann Thorac Cardiovasc Surg 2009; 15: 137

26. Bar-Or D, Lau E, Winkler JV. A novel assay for cobalt-albumin binding and its potential as a marker for myocardial ischemia a preliminary report. J Emerg Med 2000; 19: 311-5.

27. Erel Ö, Erdoğan S. Thiol-disulfide homeostasis: an integrated approach with biochemical and clinical aspects. Turk J Med Sci 2020; 50.SI-2: 1728-38. 
28. Ulusoy E, Çitlenbik H, Akgül F, et al. Is ischemia-modified albumin a reliable marker in accurate diagnosis of appendicitis in children? World J Surg 2020; 44: 1309-15.

29. Yeniocak S, Saraç F, Yazıcıoğlu M, et al. The diagnostic values of ischemia-modified albumin in patients with acute abdominal pain and its role in differentiating acute abdomen. Emerg Med Int 2020; 2020: 7925975.

30. Demir S, Dere Günal Y, Özmen İ, Dindar Badem N, Neşelioğlu S, Erel Ö. Can thiol/disulphide homeostasis help in the differential diagnosis of appendicitis in children?. Türkiye Çocuk Hast Derg 2020; 14: 236-43

31. Kaya M, Boleken ME, Kanmaz T, Erel O, Yucesan S. Total antioxidant capacity in children with acute appendicitis. Eur J Pediatr Surg 2006; 16: 34-8.

32. Nazik S, Avci V, Kiraz KZ. Ischemia-modified albumin and other inflammatory markers in the diagnosis of appendicitis in children. Ulus Travma Acil Cerrahi Derg 2017; 23: 317-21.

33. Boshnak N, M Boshnaq, Elgohary H. Evaluation of platelet indices and red cell distribution width as new biomarkers for the diagnosis of acute appendicitis. J Invest Surg 2017; 31: 1-9.

34. Koltuksuz U, Uz E, Özen S, Aydinç M, Karaman A, Akyol Ö. Plasma superoxide dismutase activity and malondialdehyde level correlate with the extent of acute appendicitis. Pediatr Surg Int 2000; 16: 559-61.

35. Fan Z, Pan J, Zhang Y, et al. Mean platelet volume and platelet distribution width as markers in the diagnosis of acute gangrenous appendicitis. Dis Markers 2015: 542013

36. Reddy VS, Perugu B, Garg MK. Ischemia-modified albumin must be evaluated as an oxidative stress marker together with albumin and bilirubin in individuals with acute appendicitis. Clinics 2015; 70: 531-2.

37. Reddy VS, Sethi S, Agrawal P, Gupta N, Garg R. Ischemia modified albumin (IMA) and albumin adjusted-IMA (AAIMA) as biomarkers for diabetic retinopathy. Nepal J Ophthalmol 2015; 7: $117-23$

38. Kılıç MÖ, Güldoğan CE, Balamir İ, Tez M. Ischemia-modified albumin as a predictor of the severity of acute appendicitis. Am J Emerg Med 2017; 35: 92-5.

39. Hakkoymaz H, Nazik S, Seyithanoğlu M, et al. The value of ischemia-modified albumin and oxidative stress markers in the diagnosis of acute appendicitis in adults. Am J Emerg Med 2019; 37: 2097-101.

40. Ayengin K, Alp HH, Avci V, Huyut Z. The effect of laparoscopic and open surgery on oxidative DNA damage and IL-37 in children with acute appendicitis. Ir J Med Sci 2021; 190: 281-9. 